\title{
Bidirectional SAR Imaging Mode
}

\author{
Josef Mittermayer, Steffen Wollstadt, Pau Prats-Iraola, Member, IEEE, Paco López-Dekker, Member, IEEE, \\ Gerhard Krieger, Senior Member, IEEE, and Alberto Moreira, Fellow, IEEE
}

\begin{abstract}
This paper introduces the bidirectional synthetic aperture radar (BiDi SAR) imaging mode, i.e., the simultaneous imaging of two directions by one antenna into one receiving channel, and presents short-term time series of images and interferograms acquired by the TerraSAR- $X$ and TanDEM-X satellites. A comparison to alternative approaches for the acquisition of short-term time series is provided. The BiDi acquisition geometry is defined, and a TerraSAR-X BiDi antenna pattern is analyzed. BiDi raw data are simulated, sampled with different pulse repetition frequency values, and compared with real BiDi raw data. The spectral separation of simultaneously acquired forward- and backward-looking images is explained. This paper presents the image results of BiDi acquisitions with TerraSAR-X and TanDEM-X satellites flying with $20-\mathbf{k m}$ along-track separation. This pursuit configuration allowed for the acquisition of up to six short-term repeated images and up to three interferograms in a single pass. An overview of potential applications for the new BiDi SAR imaging mode concludes this paper.
\end{abstract}

Index Terms-Bidirectional synthetic aperture radar (BiDi SAR), TanDEM-X, TerraSAR-X.

\section{INTRODUCTION}

$\mathbf{T}$ HE repeated acquisition of synthetic aperture radar (SAR) images has opened numerous research areas and fields of applications, such as change detection [17] or velocity measurements by along-track interferometry [15], [16]. The key parameter in the processing and the evaluation of repeated acquisitions is the time lag $t_{\text {lag }}$ between the acquisitions. In along-track interferometry, the term baseline is used. For spaceborne systems, we consider the discrimination below for $t_{\text {lag }}$ as useful.

- Long term for acquisitions that are repeated after weeks, months, or years. Example applications are the monitoring of glacier movements, erosion processes, volcanic activity, land subsidence, and urban development, e.g., [6], [7], [10]. The acquisitions can be performed by one or more satellites, typically in a repeat pass configuration.

- Midterm for repetitions within minutes, hours, or days, e.g., [18]. More satellites in constellations are required for repeated images from the same ground area under the

Manuscript received January 24, 2012; revised April 23, 2012; accepted May 20, 2012. Date of publication July 18, 2012; date of current version December 19, 2012

The authors are with the German Aerospace Center (DLR,) Microwaves and Radar Institute, Oberpfaffenhofen, 82234 Weßling, Germany. (e-mail: josef.mittermayer@dlr.de).

Color versions of one or more of the figures in this paper are available online at http://ieeexplore.ieee.org.

Digital Object Identifier 10.1109/TGRS.2012.2202669 same geometry. A possible application is flood or tidal monitoring.

- Short term with a time span of about $10 \mathrm{~ms}$ up to several seconds. Examples are iceberg drifts or ship velocity measurements [9]. More satellites flying in constellations can be used to realize short-term repeated acquisitions [8]. An example is the TanDEM-X mission [14], which flew a pursuit monostatic constellation with an alongtrack separation of approximately $3 \mathrm{~s}$ in the so-called pursuit monostatic commissioning phase [11]. In the nominal helix-like TanDEM configuration, the two satellites traverse along-track distances from zero to several hundred meters. This means that time lags from $0 \mathrm{~s}$ to about $50 \mathrm{~ms}$.

- Very short term for repetitions in the order of milliseconds or less. These repetition intervals can be obtained in a single pass by a single satellite with more than one antenna phase center in the along-track separation. An example is the Dual Receive Antenna Mode of TerraSAR-X with a time lag of $0.15 \mathrm{~ms}$ [5]. Example applications are vehicle velocity or ocean current measurements [15], [16].

This paper describes a possibility to achieve short-term repeated acquisitions with one SAR satellite only, i.e., the bidirectional (BiDi) SAR imaging mode, and presents image results obtained with the TerraSAR-X system [4], [13]. Fig. 1 shows the BiDi acquisition geometry [1].

The BiDi imaging is based on an azimuth pattern with two major lobes pointing into different directions, an increased pulse repetition frequency (PRF), and a separation of the simultaneously received images in the Doppler spectral domain. We discovered this possibility of separating images coming from different directions by analyzing highly squinted SAR data acquired with the phased array antenna of TerraSAR-X. The azimuth pattern was steered by a linear phase, which created a strong grating lobe. The principle of separating fore and aft images in the spectrum by Doppler processing was shortly mentioned by Frasier [3] in 2001 in the context of combining two directional antenna signals into one receiving channel. In our paper, we describe for the first time the use of the main lobe and one grating lobe, and present a detailed PRF-dependent analysis on the spectral separation of nonadjacent Doppler subbands. Our paper restricts to two major imaging directions and to almost symmetric backward and forward imaging, but principally, more than two imaging directions are possible and the imaging does not need to be symmetric. However, the PRF needs to be further increased, and the beam shaping becomes more complex for simultaneous acquisition into more than two directions. An alternative to obtain three directions or shortterm acquisitions of the same ground area is the combination 


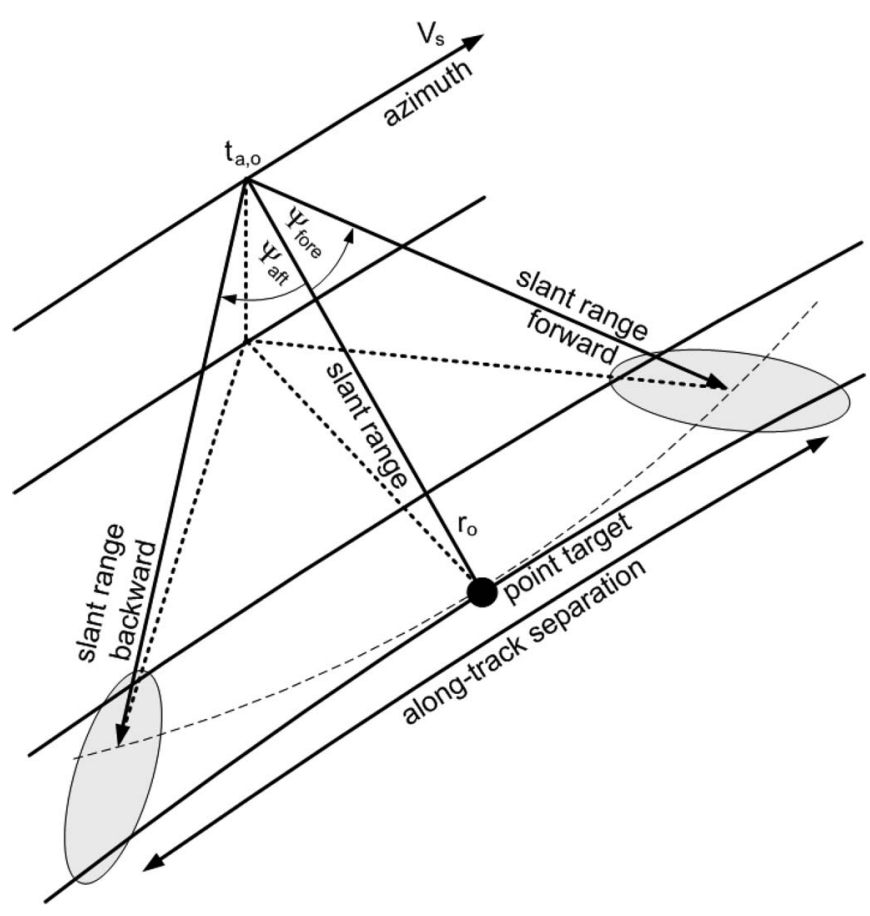

Fig. 1. BiDi acquisition geometry example with simultaneous fore and aft acquisitions.

of the BiDi with a standard boresight acquisition, as discussed in Section V.

Another motivation for the BiDi mode development is that the simultaneous imaging into two directions also means the acquisition of two widely separated Doppler subbands, which offers high-accuracy measurement of along-track displacement [22], [23], e.g., in differential interferometric SARs.

This paper is organized as follows: Section II introduces the BiDi SAR imaging mode starting from the acquisition geometry. The raw data reception, the extension of the azimuth steering beyond the grating lobe limitation, and the spectral image separation are discussed, as well as azimuth ambiguities and PRF selection. BiDi raw data simulation supports the discussion. Section III compares the BiDi mode to other approaches for short-term repeated SAR acquisitions. Section IV discusses the SAR processing and presents TerraSAR-X BiDi image pairs. Section V presents BiDi with interleaved boresight acquisition, and Section VI presents the results obtained by BiDi acquisitions in the pursuit TanDEM-X configuration, i.e., two satellites with an along-track separation of $20 \mathrm{~km}$.

\section{BIDI SAR MODE}

This section introduces the BiDi mode. The explanation of the mode is supported by the simulation of BiDi raw data by means of independent white Gaussian noise generation in the $I$ and $Q$ channels. The objective of the simulation is to show the effect of BiDi illumination into two directions on the raw data spectrum and how the spectral separation is achieved. The simulation is based on the parameter set of Table II in Appendix A, which is the parameter set of the BiDi Singapore acquisition example presented in Section IV.

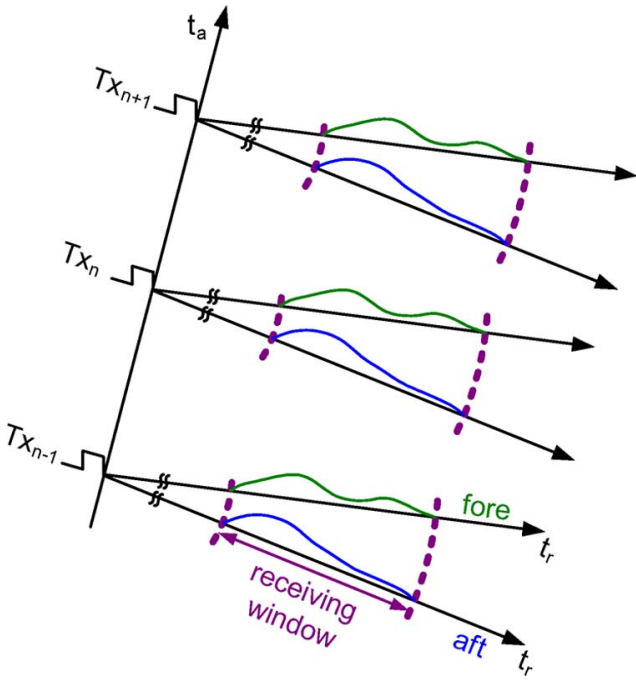

Fig. 2. BiDi data reception. The backscattered signal from the fore and aft directions are simultaneously received and superimposed into the same receiving window.

\section{A. Acquisition Geometry and Data Reception}

The direction of the strongest echo return from a target is the main beam direction of the azimuth antenna pattern, and the angle from this direction to the boresight direction is denoted by the squint angle $\psi$. In the Doppler spectrum, this direction coincides with the Doppler centroid $f_{\text {DC }}$. Fig. 1 shows the BiDi acquisition geometry for simultaneous forward and backward acquisitions in the directions $\psi_{\text {fore }}$ and $\psi_{\text {aft }}$, respectively. The azimuth direction is along the flight path, and the slant range vector in the forward direction is oriented by $90^{\circ}-\psi_{\text {fore }}$ w.r.t. azimuth. In the backward direction, the slant range vector is oriented at $90^{\circ}+\psi_{\text {aft }}$.

The same target area is acquired twice as the sensor flies by with an along-track separation in between the two illuminations. $V_{s}$ is the satellite velocity, and $V_{g}$ denotes the ground beam velocity. The closest slant range approach from the sensor to the target is $r_{o}$, and the azimuth time of the closest approach is $t_{a, o}$. The BiDi data from the fore and aft directions are simultaneously received and superimposed into the same receiving window. Fig. 2 schematically shows three transmit pulses and the corresponding receiving windows on the slant range time axes $t_{r}$.

\section{B. Extended Azimuth Steering}

The acquisition examples of this paper restrict to linear-phase steering, i.e., no dedicated antenna pattern shaping is used. By looking to the TerraSAR-X linear-phase antenna pattern simulation of Fig. 3, it can be seen that, in the array factor, the main lobe periodically repeats. The main lobe is the one that points into the desired azimuth steering direction, i.e., $+2.21^{\circ}$ in the figure. The others are denoted as grating lobes in the following. As the pattern results from weighting the array factor by the element factor in the middle plot of Fig. 3, the grating lobes are suppressed for moderate steering angles. The range of moderate steering angles depends on the antenna subarray spacing and on the element factor. 



Fig. 3. TerraSAR-X azimuth pattern simulation for a linear azimuth phase steering to $2.21^{\circ}$, no elevation steering. (Top) Resulting array factor. (Middle) Averaged element factor for horizontal polarization. (Bottom) Resulting twoway azimuth pattern.

In the TerraSAR-X system design, a limitation of $\pm 0.75^{\circ}$ was established, which corresponds to a suppression of the first grating lobes by more than $20 \mathrm{~dB}$ in the two-way pattern. This limitation is denoted as grating lobe restriction in the following. In the $\mathrm{BiDi}$ acquisition, the steering is extended beyond this limitation.

Applying a linear phase only, a convenient steering angle for $\mathrm{BiDi}$ is where the first grating lobe gets a similar element factor weighting as the main lobe. For the TerraSAR-X antenna, the angular distance between the grating lobes is

$$
\frac{\lambda}{d_{a}}=4.4^{\circ}
$$

with $\lambda$ being the wavelength and $d_{a}$ being the subarray spacing in azimuth (refer to Table II). Thus, a steering of $+2.21^{\circ}$ was applied to the array factor. After the element factor weighting, this results in the two-way pattern on the bottom of Fig. 3 with gain maxima in the $\psi_{\text {fore }}=+2.19^{\circ}$ and $\psi_{\text {aft }}=-2.22^{\circ}$ directions. These squint angles correspond to Doppler centroids of +18.96 and $-19.22 \mathrm{kHz}$, respectively. In the azimuth-pattern simulation, the gain difference between the main lobe and the grating lobe is $0.8 \mathrm{~dB}$, which is consistent with the Singapore acquisition example. However, perfectly balanced main- and grating-lobe gains can be adjusted.

\section{BiDi Raw Data Simulation}

The BiDi raw data simulation starts by generating a raw data signal with the mean normalized power of $0 \mathrm{~dB}$ by means of independent white Gaussian noise in the $I$ and $Q$ channels. The signal is sampled by a PRF of several hundred kilohertz and is

Fig. 4. BiDi raw data simulation by means of white noise in the $I$ and $Q$ channels and antenna pattern in the azimuth frequency domain. (Top) Raw data before antenna filtering with normalized mean power of $0 \mathrm{~dB}$. (Middle) Raw data spectrum after filtering by BiDi antenna pattern. (Bottom) Raw data after filtering in time domain.

thus considered as quasi-continuous. The very high generation PRF is denoted by PRF $\mathrm{Fon}_{\text {con }}$ in the following. Fig. 4 shows on the top the normalized power of the simulated raw data averaged in range. The dimension of the raw data array is $65536 \times 256$ samples in azimuth and range, respectively. Filtering the raw data with the $\mathrm{BiDi}$ azimuth pattern produces the spectrum in the middle plot of Fig. 4. The bottom plot shows the time-domain effect of selecting two small frequency bands out of the white noise.

\section{PRF and Spectral Separation}

The simultaneous reception of raw data from two directions, as illustrated in Figs. 1 and 2, is introduced into the simulation by weighting the raw spectrum with the azimuth pattern, as shown in Fig. 4. The normalized mean power of the raw data was $0 \mathrm{~dB}$, and thus, the filtered spectrum reflects the gain of the two-way pattern. Finally, the bottom plot of Fig. 4 shows the raw data in the time domain with the mean power raised by $61 \mathrm{~dB}$ due to the azimuth antenna gain.

The next simulation step is to sample the continuous raw data in azimuthby the acquisition PRF $\left(\mathrm{PRF}_{\mathrm{acq}}\right)$. In our simulation, we simply calculated the integer divisors that divide $\mathrm{PRF}_{\text {con }}$ into $\mathrm{PRF}_{\mathrm{acq}}$ values within the TerraSAR-X PRF range of Table II. Then, the downsampling is only a selection of samples without interpolation. The acquisition PRF is the key parameter for the spectral separation of the images. Fig. 5 shows the raw data after azimuth sampling with $\mathrm{PRF}_{\text {acq }}$ values of 6469,5792 , 5860 , and $2830 \mathrm{~Hz}$. The plots on the top in each frame show the azimuth pattern main lobe in the fore direction in continuous style (green) and the grating lobe in the aft direction in dashed 

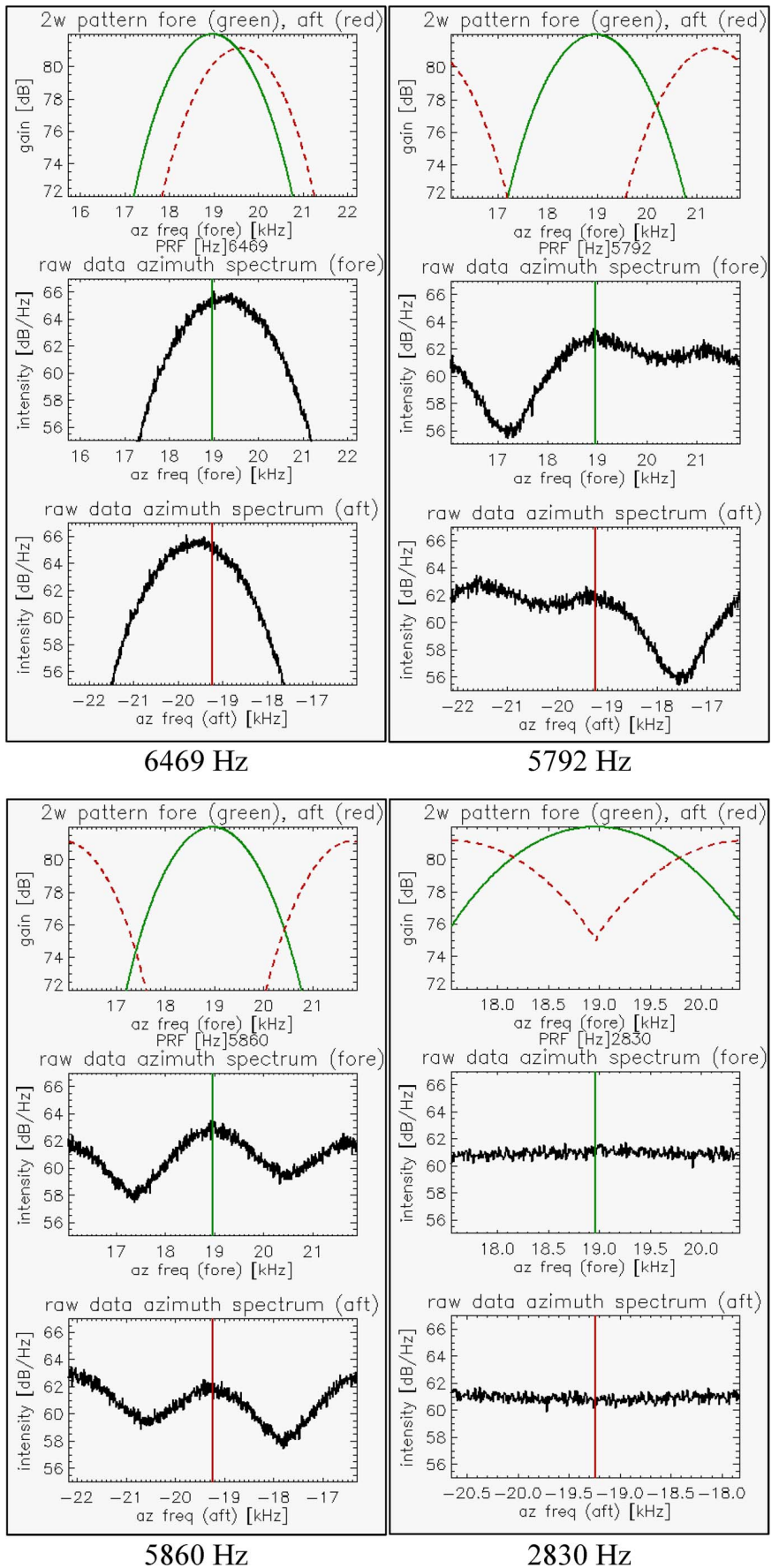

Fig. 5. Simulated azimuth pattern and simulated raw data spectra for different acquisition PRF values, i.e., 6469, 5792, 5860, and $2830 \mathrm{~Hz}$ from left top to right bottom. For each $\mathrm{PRF}_{\mathrm{acq}}$, the top plot shows the azimuth-pattern main lobe in the fore direction in the fore PRF band in (green) continuous-line style. The grating lobe in the aft direction is shown in (red) dashed style folded into the fore PRF band. The middle plots show the intensity profiles of the raw data spectra versus the fore PRF band, which is centered on (green vertical line) the fore Doppler centroid of $18.96 \mathrm{kHz}$. The bottom plots show the same profile versus the aft PRF band, centered on (red line) $-19.22 \mathrm{kHz}$.

style (red). The azimuth axis is determined by the fore PRF band. This means that the grating lobe is folded into this PRF band. The two lower plots in each frame show the intensity profile of the raw data versus the fore and aft PRF bands. The difference between the two representations is only a cyclic shift along azimuth frequency.



Fig. 6. Strategy for the selection of acquisition PRF and setting the processed azimuth bandwidth.

In the frame with $6469 \mathrm{~Hz}$ PRF, the grating lobe is folded close to the position of the main lobe. This causes a superposition of the fore and aft spectra with poor possibilities for spectral separation. The $5792 \mathrm{~Hz}$ frame shows that the grating lobe moves to the right, and the main and grating lobes can be identified in the spectrum intensity profile. In the frame for $5860 \mathrm{~Hz}$, the grating lobe moves into a very good position for spectral separation. Spectral separation can be performed by a mere bandpass filtering, i.e., selecting the processed azimuth bandwidth centered on the fore or aft Doppler centroid. Finally, in the $2830 \mathrm{~Hz}$ frame, while $\mathrm{PRF}_{\text {acq }}$ is further reduced to the low value of $2830 \mathrm{~Hz}$, several cycles of coincident- and divergent-folding constellations are passed through. As the PRF band becomes narrower, the spectra differentiation in the intensity profile is also reduced. For example, for $2830 \mathrm{~Hz}$ and divergent folding, the intensity profile becomes a constant value.

\section{E. Azimuth Ambiguities}

For well-symmetric fore and aft azimuth directions, the azimuth ambiguity to signal ratio (AASR) is connected to the spectral separation as the grating lobe is the strongest contribution of the ambiguous signal energy to the main lobe and vice versa. Thus, $\mathrm{PRF}_{\mathrm{acq}}$, which provides a good spectral separation, is also favorable in terms of the azimuth ambiguity performance. Fig. 7 shows the ambiguous azimuth signal directions for the two highest $\mathrm{PRF}_{\mathrm{acq}}$ values in Fig. 5.

The cyclic behavior of divergent and coincident folding also becomes visible by plotting the AASR versus $\mathrm{PRF}_{\text {acq }}$, as shown in Fig. 8. As the grating lobe moves relative to the main lobe, the AASR oscillates between high and low values. The high value (around $0 \mathrm{~dB}$ ) keeps constant since it reflects the coincident folding. The low value becomes lower with increasing PRF since, in the divergent folding, the separation improves with increasing PRF. The dashed line represents the AASR in the aft image and is higher than the continuous one of the fore image. The reason is that the backward-looking grating lobe in the example is $0.8 \mathrm{~dB}$ below the forward-looking main lobe, and thus, the AASR is slightly worse in the aft image. For perfect equalized main- and grating-lobe gains, both curves would be identical. 


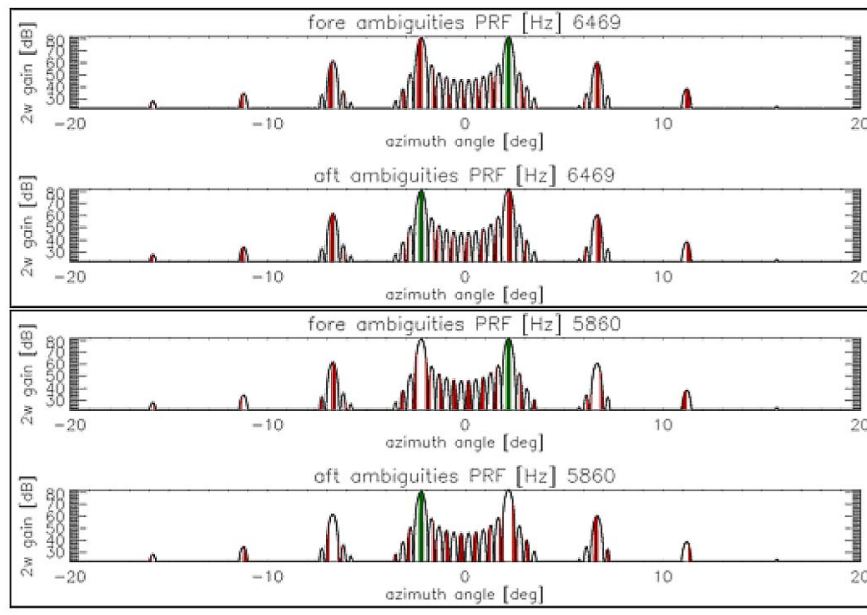

Fig. 7. (Red) Ambiguous signal values and (green) coverage directions for $\mathrm{PRF}_{\text {acq }}$ causing (top) coincident $(6469 \mathrm{~Hz})$ and (bottom) divergent $(5860 \mathrm{~Hz})$ grating-lobe folding. The processed bandwidth is $70 \%$ of the 3 -dB bandwidth.

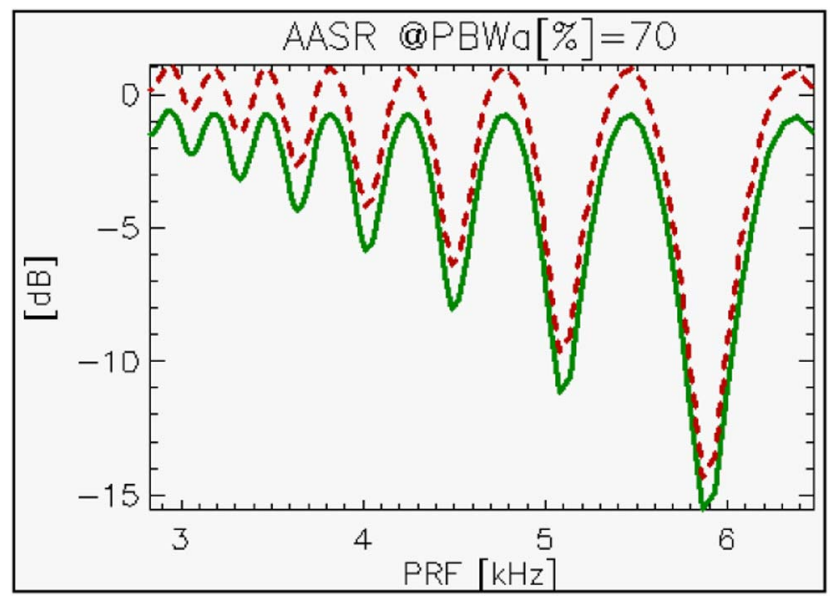

Fig. 8. AASR versus acquisition PRF. The processed bandwidth is $70 \%$ of the 3-dB bandwidth and no sidelobe suppression weighting is applied. (Continuous-line style in green) AASR in the fore image. (Dashed line style in red) AASR in the aft image.

\section{F. Selection of Acquisition PRF}

The block diagram in Fig. 6 shows the basic approach to set the acquisition $\mathrm{PRF}_{\mathrm{acq}}$. The starting point is a desired on-ground azimuth separation of fore and aft images, from which the fore and aft azimuth steering angles $\psi_{\text {fore }}$ and $\psi_{\text {aft }}$ are estimated. Antenna pattern shaping should provide some flexibility for the steering-angle selection. However, a linearphase steering to an angle where the main and grating lobes show equal gain is an optimum antenna shape and is used in the TerraSAR-X Singapore example with a steering of $\pm 2.2^{\circ}$.

From fore and aft azimuth steering angles, the best PRF for the spectra separation is estimated, i.e., PRF sep $_{\text {in Fig. } 6 .}$ As the spectra separation is connected with the AASR (wellsymmetric fore and aft directions), this can be done by looking for the minimum AASR (refer to previous section). In parallel, the acquisition timing parameters [4] need to be calculated from the acquisition geometry, the PRF among others. The result is a set of possible timing PRF values, i.e., $\mathrm{PRF}_{\mathrm{tim}}$ in Fig. 6, which are adequate for the avoidance of nadir and transmit



Fig. 9. (Left) Single-look stripmap and (right) two-look stripmap acquisition.

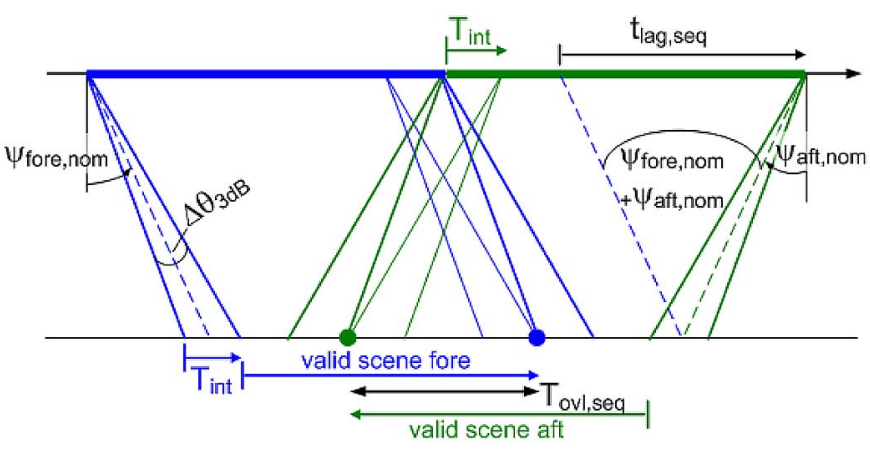

Fig. 10. Time lag for sequential fore/aft stripmap acquisition.

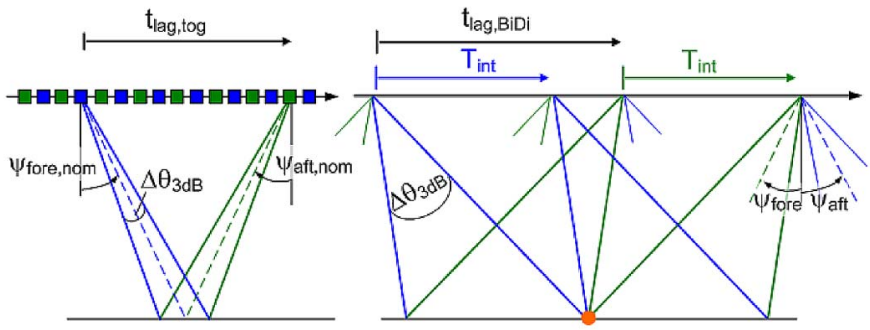

Fig. 11. Time lag for toggling fore/aft (left) stripmap acquisition and (right) BiDi acquisition.

interferences. Finally, a tradeoff between $\mathrm{PRF}_{\text {sep }}$ and $\mathrm{PRF}_{\text {tim }}$ results in the PRF selected for the acquisition, i.e., $\mathrm{PRF}_{\text {acq }}$. In the processing, the desired AASR is finally adjusted by the processed azimuth bandwidth $B_{\text {proc }}$.

\section{Single-Satellite Short-Term REPEATED ACQUISITIONS}

This section discusses other approaches for short-term repeated SAR imaging and compares them against BiDi. In a stripmap SAR acquisition, the processed azimuth angle span $\Delta \theta_{\text {proc }}$ is usually in the order of the 3-dB azimuth beamwidth $\Delta \theta_{3} \mathrm{~dB}$. The PRF is usually selected slightly higher than the azimuth bandwidth $B_{3 \mathrm{~dB}}$, which corresponds to $\Delta \theta_{3 \mathrm{~dB}}$. For the following discussion, $\Delta \theta_{\text {proc }}$ is set equal to $\Delta \theta_{3 \mathrm{~dB}}$, i.e.,

$$
\begin{aligned}
B_{\text {proc }} & =\frac{2 \cdot V_{s}}{\lambda} \cdot \sin \left(\Delta \theta_{\text {proc }}\right) \\
\stackrel{!}{=} B_{3 \mathrm{~dB}} & =\frac{2 \cdot V_{s}}{\lambda} \cdot \sin \left(\Delta \theta_{3 \mathrm{~dB}}\right)<\mathrm{PRF}_{\text {strip }} .
\end{aligned}
$$

$\mathrm{PRF}_{\text {strip }}$ is the PRF of the stripmap acquisition, $V_{s}$ is the satellite velocity, and $\lambda$ is the wavelength. With $V_{g}$ being the 
ground beam velocity, the target integration time for single-look $T_{\text {int }}$ is then defined by

$$
T_{\mathrm{int}}=\frac{r_{0} \cdot \Delta \theta_{3 \mathrm{~dB}}}{V_{g}}
$$

\section{A. Multilook Stripmap Approach}

A short-term repeated acquisition can be obtained by dividing the processed azimuth angle span into $n_{L}$ azimuth looks. This is discussed in the literature, e.g., for the measurement of the azimuth velocity component of moving targets [2]. Fig. 9 shows the integration time $T_{\text {int }}$ for a single-look stripmap acquisition on the left and the reduced integration time per look $T_{\text {int,multi }}$ for processing two azimuth looks on the right. The azimuth time lag $t_{\text {lag,multi }}$ between the outer looks in a repeated look acquisition with $n_{L}$ looks is

$$
t_{\text {lag,multi }}=\frac{r_{0} \cdot \Delta \theta_{3 \mathrm{~dB}}}{V_{g}} \cdot\left(1-\frac{1}{n_{L}}\right) .
$$

The theoretical maximum time lag between the outer looks for $n_{L} \rightarrow \infty$ is

$$
t_{\mathrm{lag}, \text { multi,max }}=\frac{r_{0} \cdot \Delta \theta_{3 \mathrm{~dB}}}{V_{g}}=T_{\mathrm{int}} .
$$

For the parameter set of the Singapore example in Fig. 15 of Section IV, $t_{\text {lag,multi,max }}$ is $0.44 \mathrm{~s}$, and it is $0.22 \mathrm{~s}$ for two looks. The disadvantage of the multilook approach is the relatively small time lag and that the integration time needs to be shared between the looks, which means a reduced azimuth resolution. The images overlap time $T_{\text {ovl }}$ is the common image area of fore and aft images. In the multilook approach, $T_{\text {ovl,multi }}$ is not limited by the acquisition geometry, i.e., it is equal to the acquisition length (neglecting the azimuth filter length).

\section{B. Sequential Fore/Aft Stripmap Approach}

A short-term repeated acquisition can be obtained by a forward-steered stripmap acquisition followed by a backwardsteered one, as shown in Fig. 10. The fore and aft steering angles need to be within the nominal steering-angle range, i.e., $\psi_{\text {fore,nom }} / \psi_{\text {aft,nom }}= \pm 0.75^{\circ}$ in the case of TerraSAR-X. The time lag is

$$
t_{\text {lag, seq }}=\frac{r_{0} \cdot\left(\Psi_{\text {fore,nom }}-\Psi_{\text {aft,nom }}\right)}{V_{g}}
$$

and results with the example parameters to $t_{\text {lag,seq }}=2 \mathrm{~s}$. The images overlap results to

$$
T_{\text {ovl,seq }}=\frac{r_{0} \cdot\left(\Psi_{\text {fore,nom }}-\Psi_{\text {aft,nom }}-\Delta \theta_{3 \mathrm{~dB}}\right)}{V_{g}}
$$

which is $1.6 \mathrm{~s}$ for the Singapore parameters or $11.1 \mathrm{~km}$ onground. The disadvantage of this approach is the limitation of the image overlap and the time lag restriction imposed by the nominal steering-angle range. The advantage is that the standard stripmap $\mathrm{PRF}_{\text {strip }}$ is kept, as well as the azimuth resolution.

\section{Toggling Fore/Aft Stripmap Approach}

A possibility to overcome the limitation of the image overlap in the sequential fore/aft stripmap approach is to toggle between fore and aft illumination from pulse to pulse, as is, for example, possible in TerraSAR-X. Fig. 11 shows on the left the toggling fore/aft stripmap approach. The image overlap is equal to the length of the acquisition and is thus not limited apart from power, temperature, or memory limitations. The time lag $t_{\text {lag,tog }}$ in the toggling fore/aft stripmap approach is identical to the one of the sequential approach, i.e., $t_{\text {lag,tog }}=2 \mathrm{~s}$ for the Singapore parameters. The disadvantage of the approach is the doubled acquisition PRF compared with $\mathrm{PRF}_{\text {strip. }}$. On the other hand, the PRF in each virtual channel allows for the full stripmap resolution.

\section{Comparison with the BiDi Approach}

Fig. 11 shows the BiDi imaging mode on the right. Due to the extension of the azimuth steering angles beyond the gratinglobe restriction, i.e., $\left|\psi_{\text {aft/fore }}\right|>\left|\psi_{\text {aft,nom/fore,nom }}\right|$, the time $\operatorname{lag} t_{\mathrm{lag}, \mathrm{BiDi}}$, i.e.,

$$
t_{\mathrm{lag}, \mathrm{BiDi}}=\frac{r_{0} \cdot\left(\Psi_{\mathrm{fore}}-\Psi_{\mathrm{aft}}\right)}{V_{g}}
$$

outperforms the sequential and toggling fore/aft stripmap approaches. For the Singapore acquisition example, $t_{\mathrm{lag}, \mathrm{BiDi}}$ is $5.9 \mathrm{~s}$, which is one order of magnitude larger than for the multilook stripmap approach and three times the value of both fore/aft stripmap approaches. However, $t_{\mathrm{lag}, \mathrm{BiDi}}$ can be adjusted by antenna pattern shaping to smaller or larger values under the consideration of azimuth ambiguities and signal-tonoise ratio (SNR).

As in the toggling fore/aft stripmap approach, the image overlap is equal to the length of the acquisition and is, apart from satellite resources, unlimited. The disadvantage of doubled acquisition PRF also applies to the BiDi approach. In contrast to the sequential and toggling fore/aft acquisition approaches, the BiDi data from the fore and aft directions are simultaneously received and superimposed into the same receiving window. In principle, this is identical to the multilook approach, but the looks in BiDi are not adjacent, neither in azimuth time nor frequency.

Table I summarizes the comparison of the different approaches for short-term repeated SAR acquisition exemplarily for the Singapore acquisition parameter example in Table II.

In Table I, two more approaches are added, which allow repeated acquisition with one satellite and one channel, i.e., the repeated ScanSAR [12] and terrain observation by progressive scan (TOPS) [20], [21] modes. The principle is not to scan the subswathes in elevation but to repeat the acquisition of the same subswath. The most obvious discrimination of these modes w.r.t. $\mathrm{BiDi}$ and the other approaches is the variation of the Doppler centroid with the targets' azimuthal position. Also, the SNR and the azimuth ambiguity vary along azimuth. Appendix B details the repeated ScanSAR and TOPS modes for short-term repeated acquisition. We consider these two modes to be complementary to the other modes of Table I, which are based on the stripmap acquisition and a show constant SAR 
TABLE I

SHORT-TERM SAR REPEATED ACQUISITION APPROACHES

\begin{tabular}{|c|c|c|c|c|c|c|c|}
\hline & $\begin{array}{c}\text { Stripmap } \\
1 \text { look }\end{array}$ & $\begin{array}{c}\text { tripmap } \\
2 \text { look }\end{array}$ & $\begin{array}{c}\text { Sequential } \\
\text { fore/aft }\end{array}$ & $\begin{array}{c}\text { Toggling } \\
\text { fore/aft }\end{array}$ & BiDi & $\begin{array}{c}\text { Repeated } \\
\text { ScanSAR* }\end{array}$ & $\begin{array}{c}\text { Repeated } \\
\text { TOPS* }\end{array}$ \\
\hline$\theta_{\text {steer,max }}$ & $0^{\circ}$ & $0^{\circ}$ & $0.75^{\circ}$ & $0.75^{\circ}$ & $\mathbf{2 . 2}^{\circ}$ & $0^{\circ}$ & $0.75^{\circ}$ \\
\hline time lag & -- & $0.22 \mathrm{~s}$ & $2 \mathrm{~s}$ & $2 \mathrm{~s}$ & $\mathbf{5 . 9} \mathrm{s}$ & $0.15 \mathrm{~s}$ & $1.6 \mathrm{~s}$ \\
\hline $\begin{array}{c}\text { images } \\
\text { overlap }\end{array}$ & -- & no limit & $1.6 \mathrm{~s}$ & no limit & no limit & no limit & no limit \\
\hline $\begin{array}{c}\text { image az. } \\
\text { extension }\end{array}$ & no limit & no limit & $\mathrm{N} / \mathrm{A}$ & no limit & $\mathbf{n o ~ l i m i t ~}$ & no limit & no limit \\
\hline $\begin{array}{c}\text { acquisi- } \\
\text { tion PRF }\end{array}$ & $\mathrm{PRF}_{\text {strip }}$ & $\mathrm{PRF}_{\text {strip }}$ & $\mathrm{PRF}_{\text {strip }}$ & $\begin{array}{c}2 \mathrm{x} \\
\mathrm{PRF}_{\text {strip }}\end{array}$ & $\begin{array}{c}\mathbf{2 x} \\
\mathbf{P R F}_{\text {strip }}\end{array}$ & $\mathrm{PRF}_{\text {strip }}$ & $\mathrm{PRF}_{\text {strip }}$ \\
\hline $\begin{array}{c}\text { azimuth } \\
\text { resolution }\end{array}$ & $\rho_{\mathrm{az}}$ & $2 \cdot \rho_{\mathrm{az}}$ & $\rho_{\mathrm{az}}$ & $\rho_{\mathrm{az}}$ & $\mathbf{\rho}_{\text {az }}$ & $3 \cdot \rho_{\mathrm{az}}$ & $2.3 \cdot \rho_{\mathrm{az}}$ \\
\hline $\mathrm{SNR}$ & $\mathrm{SNR}_{\text {strip }}$ & $\mathrm{SNR}_{\text {strip }}$ & $\begin{array}{c}\mathrm{SNR}_{\text {strip }} \\
-0.5 \mathrm{~dB}\end{array}$ & $\begin{array}{c}\mathrm{SNR}_{\text {strip }} \\
-0.5 \mathrm{~dB}\end{array}$ & $\begin{array}{c}\mathbf{S N R}_{\text {strip }} \\
-\mathbf{3 . 7} \mathbf{d B}\end{array}$ & $\begin{array}{c}\mathrm{SNR}_{\text {strip }} \\
-0.9 \mathrm{~dB}\end{array}$ & $\begin{array}{c}\mathrm{SNR}_{\text {strip }} \\
-0.2 \mathrm{~dB}\end{array}$ \\
\hline
\end{tabular}

Comparison for Singapore Parameter Set. ${ }^{*}$ The repeated ScanSAR and TOPS approaches are described in Appendix II.

performance along azimuth. The discussion below applies to Table I.

- Compared with stripmap, the SNR of the BiDi approach is reduced by $3.7 \mathrm{~dB}$ for equal main- and grating-lobe gains since the element pattern decreases with the steering angle (refer to Fig. 3). In sequential and toggling fore/aft steering, the reduction is $0.5 \mathrm{~dB}$ due to the steering to $\pm 0.75^{\circ}$. For two azimuth looks, the SNR does not change. Note that, in the case that the duty cycle is kept constant when the PRF is doubled, the SNR is reduced by another $3 \mathrm{~dB}$ for toggling fore/aft steering and $\mathrm{BiDi}$, i.e., -3.5 and $-6.7 \mathrm{~dB}$, respectively.

- Along with an increased acquisition PRF, it may be necessary to reduce the swath width since the receiving window length plus the transmitted pulse length needs to be smaller than one pulse repetition interval.

- The SNR deterioration values for ScanSAR and TOPS repeated approaches are worst case values for the outer targets of a processed image burst.

- The maximum azimuth steering angle is set to $2.2^{\circ}$ for $\mathrm{BiDi}$, which results in equal main- and grating-lobe gains for pure linear-phase azimuth-pattern excitation. With advanced azimuth-pattern shaping, this limitation may no longer apply.

- The image azimuth extension for sequential fore/aft stripmap is set to not applicable (N/A) since the possible unlimited extension of the fore and aft images in azimuth is useless without matchable overlap.

\section{TerRASAR-X BiDi ACQUisition EXAMPLE}

This section compares a real TerraSAR-X BiDi acquisition to the raw data simulation results of Section II, discusses the BiDi SAR processing, and presents Singapore-harbor-area BiDi images. An additional TerraSAR-X BiDi image example showing fjords in Norway can be found in [1].

\section{A. Raw Data and Spectral Separation}

The power profile of the simulated continuous raw data of Fig. 4 is shown in Fig. 12 on the top after azimuth sampling
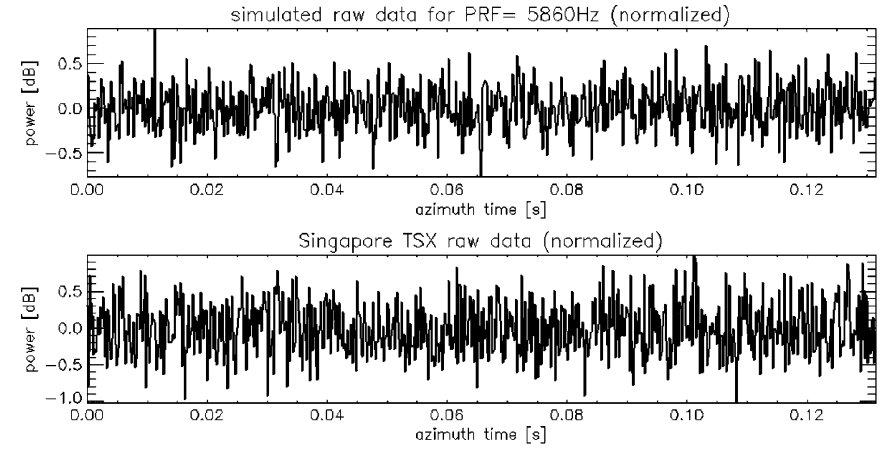

Fig. 12. Power profile averaged from 256 range samples. (top) Simulated raw data after azimuth sampling with $\mathrm{PRF}_{\text {acq }}$ of $5860 \mathrm{~Hz}$. (bottom) Real TerraSAR-X raw data (same $\mathrm{PRF}_{\mathrm{acq}}$ ).


Fig. 13. Intensity profile of raw data from TerraSAR-X BiDi acquisition. Raw data block with $8192 \times 16834$ azimuth and range samples, respectively. $\mathrm{PRF}_{\text {acq }}$ is $5860 \mathrm{~Hz}$. (Left) Spectrum in the PRF band centered around the fore Doppler centroid $f_{\mathrm{DC}}$ in green. (Right) Centered around the aft Doppler centroid in red.

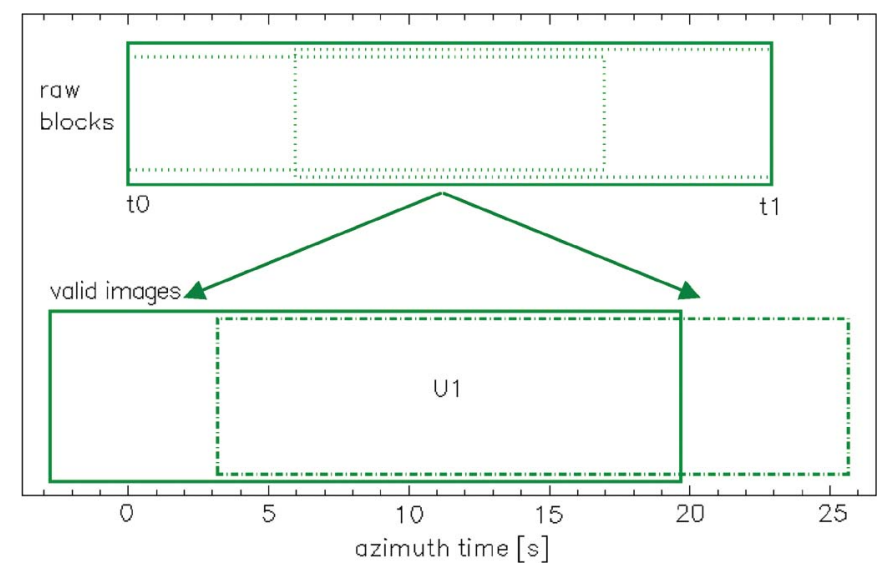

Fig. 14. Azimuth position of raw data blocks and valid images for the Singapore acquisition. Fore and aft images are separated by $5.9 \mathrm{~s}$.

with a $\mathrm{PRF}_{\mathrm{acq}}$ value of $5860 \mathrm{~Hz}$. The bottom plot shows the power profile of a sequence of real TerraSAR-X raw data. Both profiles are generated by averaging over 256 range lines. The simulated spectral filtering models very well the azimuthpattern weighting of the real raw data and thus leads to a similar structure in real and simulated raw data. This becomes obvious by looking to the real raw spectrum in Fig. 13, which is the superposition of all folded azimuth frequencies and agrees well with the simulated one in Fig. 5 for $5860 \mathrm{~Hz}$ PRF. Since the steering-angle difference is $4.4^{\circ}$ and, thus, the scene contents in the main- and grating-lobe directions vary, differences to the simulated raw data spectrum are scene-content dependent and expected. 


\section{B. Fore and Aft Image Processing}

Table II in Appendix A summarizes the system, processing, and image parameters for the Singapore acquisition. The TerraSAR-X raw data are first transformed into range Doppler domain, and the spectrum is separated into fore and aft spectra by applying the azimuth sidelobe suppression weighting function with limitation to processed bandwidth once centered around the fore Doppler centroid $f_{\mathrm{DC}}$ and once centered around the aft Doppler centroid, respectively (refer to Fig. 13). Then, the processing is separately carried out for the fore and aft images following the classical extended chirp scaling approach for stripmap [12].

As customary in the SAR image processing, the SAR raw data were converted into zero Doppler geometry, i.e., the focused targets were located at the azimuth time position of closest approach $t_{a, 0}$ (refer to Fig. 1).

Fig. 14 shows the azimuth position of raw data and valid images as calculated during the SAR processing. On the top of Fig. 14, the raw data are extended in the azimuth time from $t_{0}$ to $t_{1}$ and plotted in continuous-line style. On the bottom, the valid processed aft image is in continuous-line style, and the fore image is in dashed style. The time lag between fore and aft image is $5.9 \mathrm{~s}$, which corresponds to a distance of $42 \mathrm{~km}$ on-ground. In Fig. 14, U1 is the overlapping area between the valid fore and aft images with an azimuth extension of $16.5 \mathrm{~s}$ or $117.5 \mathrm{~km}$ on-ground. On top, the dashed style rectangles show which parts of the raw data blocks need to be selected for processing only the overlap area U1.

Fig. 15 shows the resulting fore (left) and aft (right) images of the Singapore acquisition. The yellow box in the images indicates the harbor area onto which Fig. 16 zooms. At the image positions where the backscatter value is high and is equal in both images, the colors combine to yellow. There are a number of nonmoving manmade targets that already show a considerable difference in the backscatter due to the acquisition azimuth angle difference of $4.4^{\circ}$. The motion of ships is clearly visible (see Section VI-A).

\section{BiDi With Interleaved Boresight ACQUisition}

By combining the BiDi acquisition with a boresight acquisition, it is possible to generate a single-satellite short-term series of three acquisitions of the same target area. The antenna is switched from BiDi to boresight acquisition and again back to the BiDi imaging mode. An example acquisition with this method was executed over the Upsala glacier in Argentina by TerraSAR-X. The incidence angle was $42^{\circ}$, and the acquisition PRF was $5790 \mathrm{~Hz}$. The antenna azimuth steering angles of $+2.2^{\circ}, 0^{\circ}$, and $-2.2^{\circ}$ result in a repetition interval of $3.6 \mathrm{~s}$ between the three acquisitions. Due to the doubled PRF and the high incidence angle, the swath width is $22.2 \mathrm{~km}$ in ground range, which is less than the standard TerraSAR-X stripmap swath width of $30 \mathrm{~km}$.

Fig. 17 shows, for the Upsala acquisition, the azimuth position of the raw data blocks and the processed images. A raw data block in this context means a raw data section with constant azimuth pattern. The azimuth time is on the $x$-axis. The raw data blocks are shown on top, at the actual azimuth


Fig. 15. TerraSAR-X BiDi acquisition of Singapore. (Left) Fore image. (Right) Aft image. The azimuth direction is on the left, from bottom to top. (Yellow box) Harbor area onto which Fig. 16 zooms. The images include land, sea, urban area, and several ships. Ships are either moving or anchoring near the harbor. 


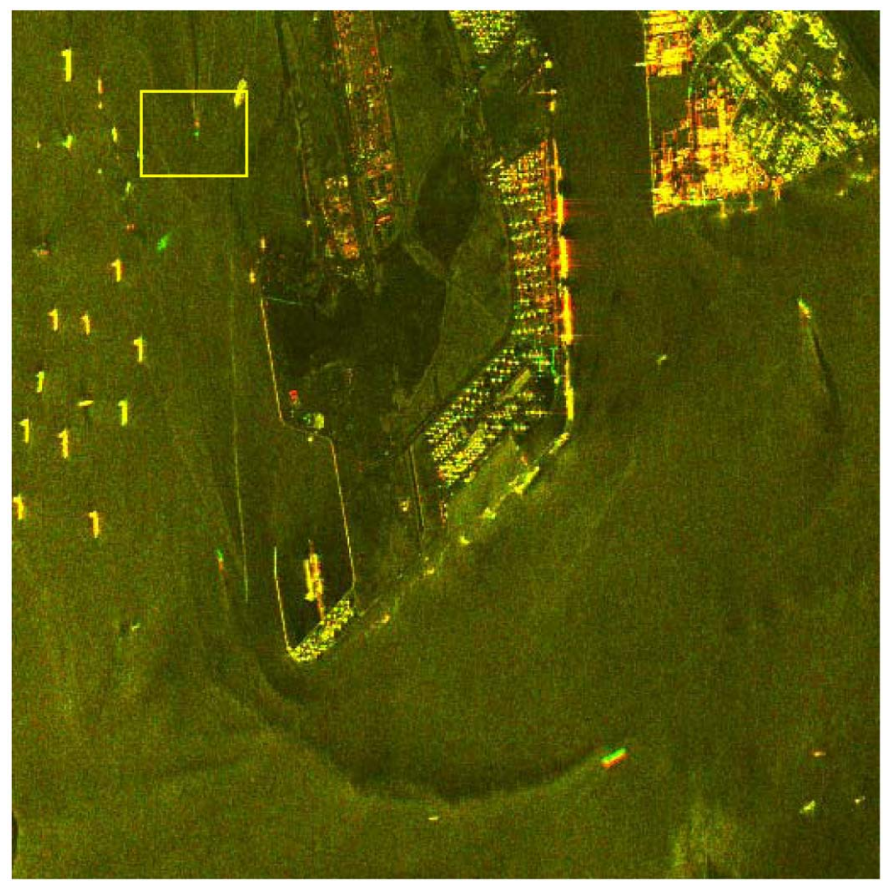

Fig. 16. Color composite of (red) fore and (green) aft TerraSAR-X Singapore acquisition. The azimuth direction is on the left, from bottom to top. Zoomed detail of Fig. 15.

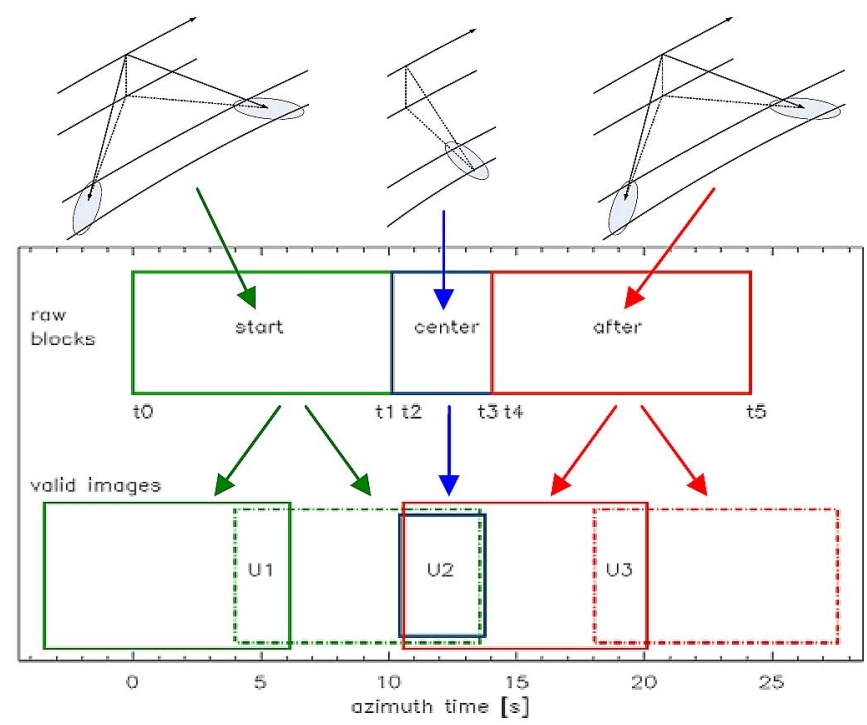

Fig. 17. Azimuth position of raw data blocks and valid images for Upsala acquisition. The imaging mode was switched from BiDi to boresight after the acquisition of the start raw data block and switched back to BiDi after center block acquisition.

time positions. The azimuth position of the corresponding images is shown on the bottom. The starting raw data block was acquired from $t_{0}$ to $t_{1}$ in the BiDi mode. It is green and produces the green valid images on the bottom, the aft image in continuous-line style, and the fore image in dashed style. Then, the antenna was switched to boresight, and the blue raw data block from $t_{2}$ to $t_{3}$ was acquired, corresponding to the valid image in blue on the bottom. Finally, the after-raw-data block was again acquired in the BiDi mode (red color) from $t_{4}$ to $t_{5}$, and the corresponding fore and aft images were obtained.

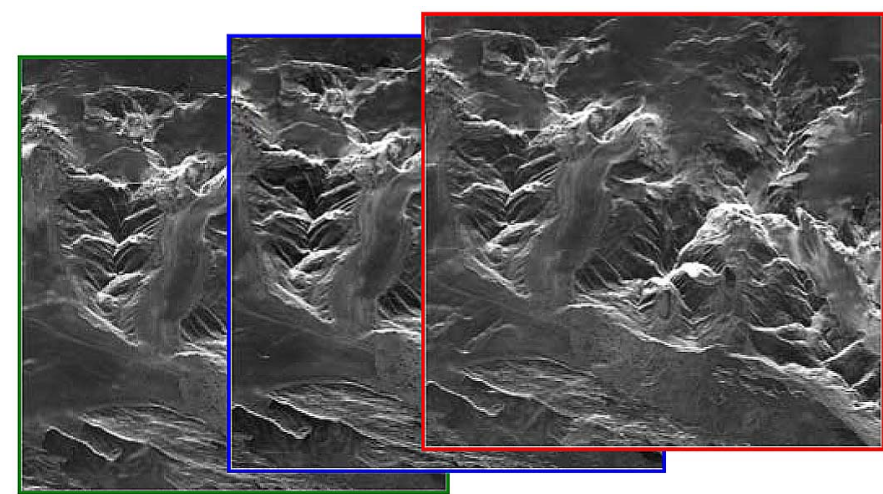

Fig. 18. Single-satellite short-time series with three repeated acquisitions over the Upsala glacier. The overlap area U2 from Fig. 17 is first imaged in BiDimode fore direction into the start raw data block, then in the boresight mode, and stored into the center raw data block. Finally, it is again imaged in $\mathrm{BiDi}$ mode into the aft direction and stored into the after-raw-data block.
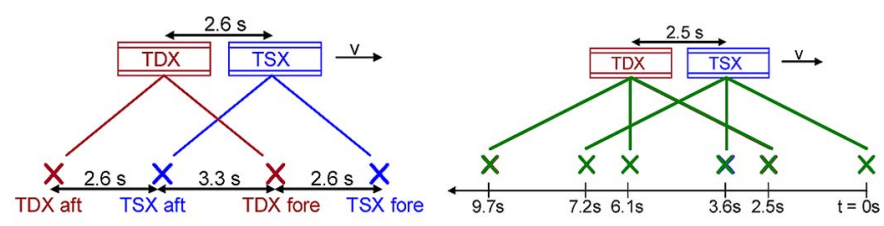

Fig. 19. TanDEM-X pursuit monostatic acquisition constellation of TerraSAR-X and TanDEM-X satellites during (left) the Singapore acquisition and (right) the Upsala glacier acquisition.

As shown in the lower part of the plot, the valid images are overlapping. The image overlap area U1 in Fig. 17 originates from the start raw data block only, just as U3 originates from the after raw block. Fig. 18 shows the overlap area U2, imaged three times during the start, the center, and after-raw-data block acquisition.

\section{BiDi ACQUisitions in Pursuit MonostatiC TANDEM-X CONFIGURATION}

The unique acquisition geometry available in the TanDEM-X pursuit monostatic commissioning phase [11] allowed for BiDi acquisitions with two satellites flying with an along-track separation of $20 \mathrm{~km}$. Both the Singapore acquisition and the Upsala glacier acquisition were carried out in this constellation. This section demonstrates the advanced possibilities of BiDi in case of the availability of two satellites flying in along-track separation. A short-time series of 4 images was created for the Singapore example. For the Upsala example, a six-image time series was first created and then combined to a series of three interferograms.

\section{A. Four-Image Time-Series Singapore Example}

Fig. 19 schematically shows the constellation of the Singapore acquisition on the left. The TanDEM-X satellite follows the TerraSAR-X satellite at a distance of about $2.6 \mathrm{~s}$. Both satellites operate in BiDi mode with simultaneous fore/aft acquisitions at $\pm 2.2^{\circ}$ directions, which corresponds to a repetition time of $5.9 \mathrm{~s}$ for each individual satellite. Thus, in the 


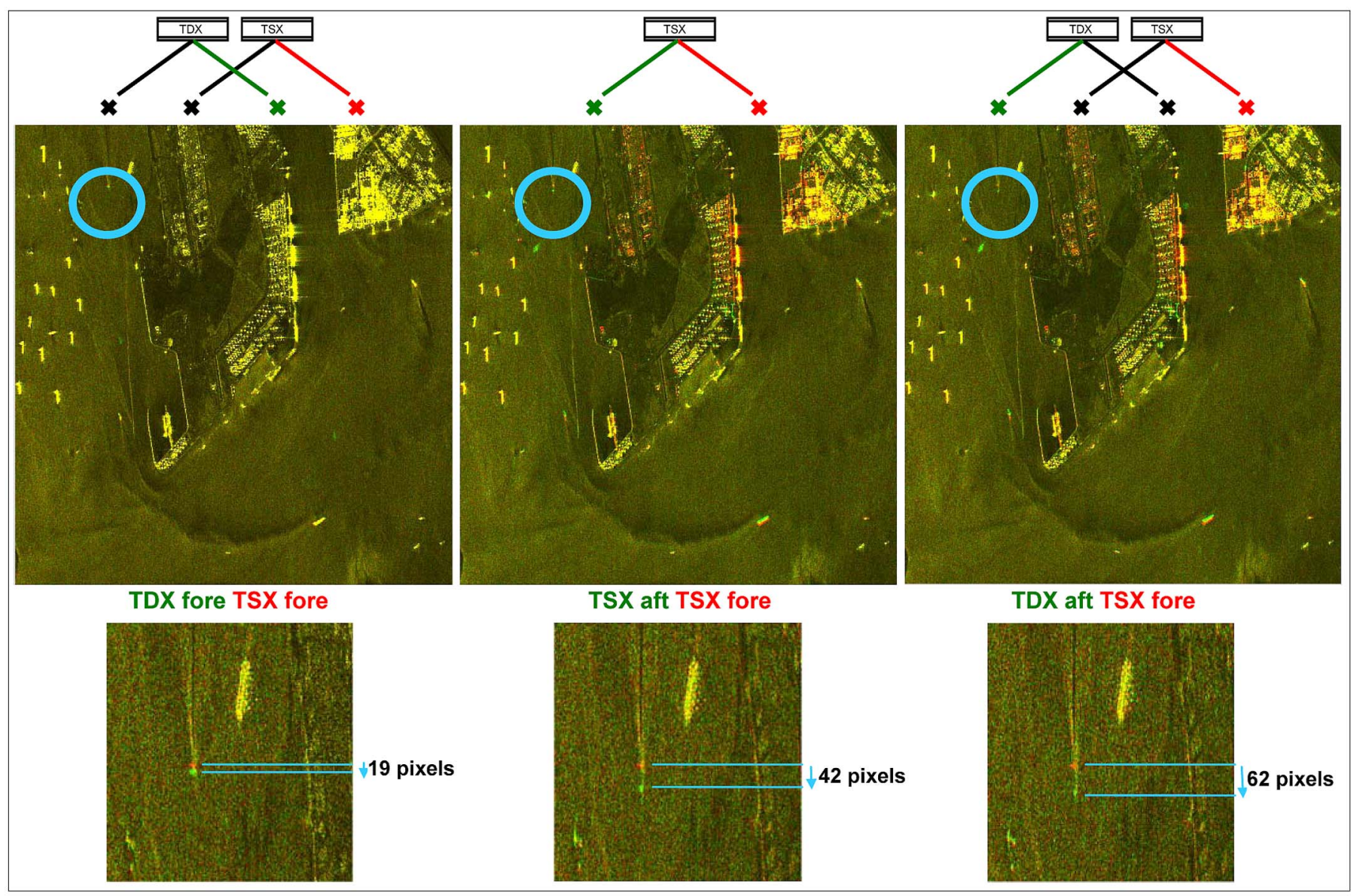

Fig. 20. Color composite of zooms into TerraSAR-X (TSX) and TanDEM-X (TDX) fore and aft images. Azimuth direction is on bottom from left to right.

constellation, four images were acquired with time separations of 2.6 and $3.3 \mathrm{~s}$, as indicated in the figure.

Fig. 20 shows, in the left column, the color composite of the TerraSAR-X fore image in red and the TanDEM-X fore image in green. Due to the same azimuth acquisition angle of $+2.2^{\circ}$, the backscatter is almost identical in both images (refer to Fig. 16 and the yellow color prevails). As indicated in Fig. 19 on the left, the time separation is $2.6 \mathrm{~s}$. The blue circle indicates a ship moving fast into the negative azimuth direction (visible from the wake). The smaller image on the bottom zooms onto this ship. By simply counting the pixels between the ship positions in the TerraSAR-X fore and TanDEM-X fore images, the velocity was estimated to about $6.1 \mathrm{~m} / \mathrm{s}$. The center top image compares the TerraSAR-X fore and aft images. The difference in the ship position is 42 pixels. The right column images finally compare the TerraSAR-X fore and TanDEM-X aft images. An azimuth velocity causes a change in the azimuth position of the ship, in the case of two satellites and for one satellite in fore and aft imaging. The backscatter dependence on the azimuth acquisition angle is clearly visible in the right and mid-images. Note the striking degree of similarity between the two difference images, which is due to the identical angle difference of $4.4^{\circ}$. For comparison, no pronounced backscatter differences can be observed in the left image, demonstrating that the backscatter difference is a pure effect of the aspect angle and not induced by a residual cross-track baseline between TerraSAR-X and TanDEM-X.

\section{B. Three-Interferogram Series Upsala Example}

Fig. 19 shows on the right the acquisition constellation for the overlap area U2 of Fig. 17. The first image acquired is TerraSAR-X fore, followed by TanDEM-X fore after $2.5 \mathrm{~s}$, etc. With the acquisition scheme described in Fig. 17, a shorttime series of six images was obtained and combined to a series of three interferograms with azimuth time offsets of 3.6 and 7.2 s. Fig. 21 shows the three interferograms obtained from fore-, center-, and aft-looking images in the form of an interferogram overlay onto the SAR amplitude images. The azimuth extension of the three interferograms is $20 \mathrm{~km}$.

\section{CONCLUSION}

The BiDi imaging mode allows for single-satellite short-term repeated SAR acquisitions in the range of seconds. A classification into long-, mid-, short-, and very-short-term acquisition repetition intervals has been introduced. The BiDi geometry has been introduced for symmetric fore/aft imaging. In principle, more directions can be simultaneously acquired, requiring more effort in antenna pattern shaping and PRF selection.

In $\mathrm{BiDi}$, the raw data from different directions simultaneously arrive at the sensor and are superimposed into the same receiving window. BiDi raw data have been simulated, and the raw data spectrum has been analyzed for varying PRF values. Good accordance was found with the raw data and the raw data spectrum of real TerraSAR-X BiDi acquisitions. The separation 


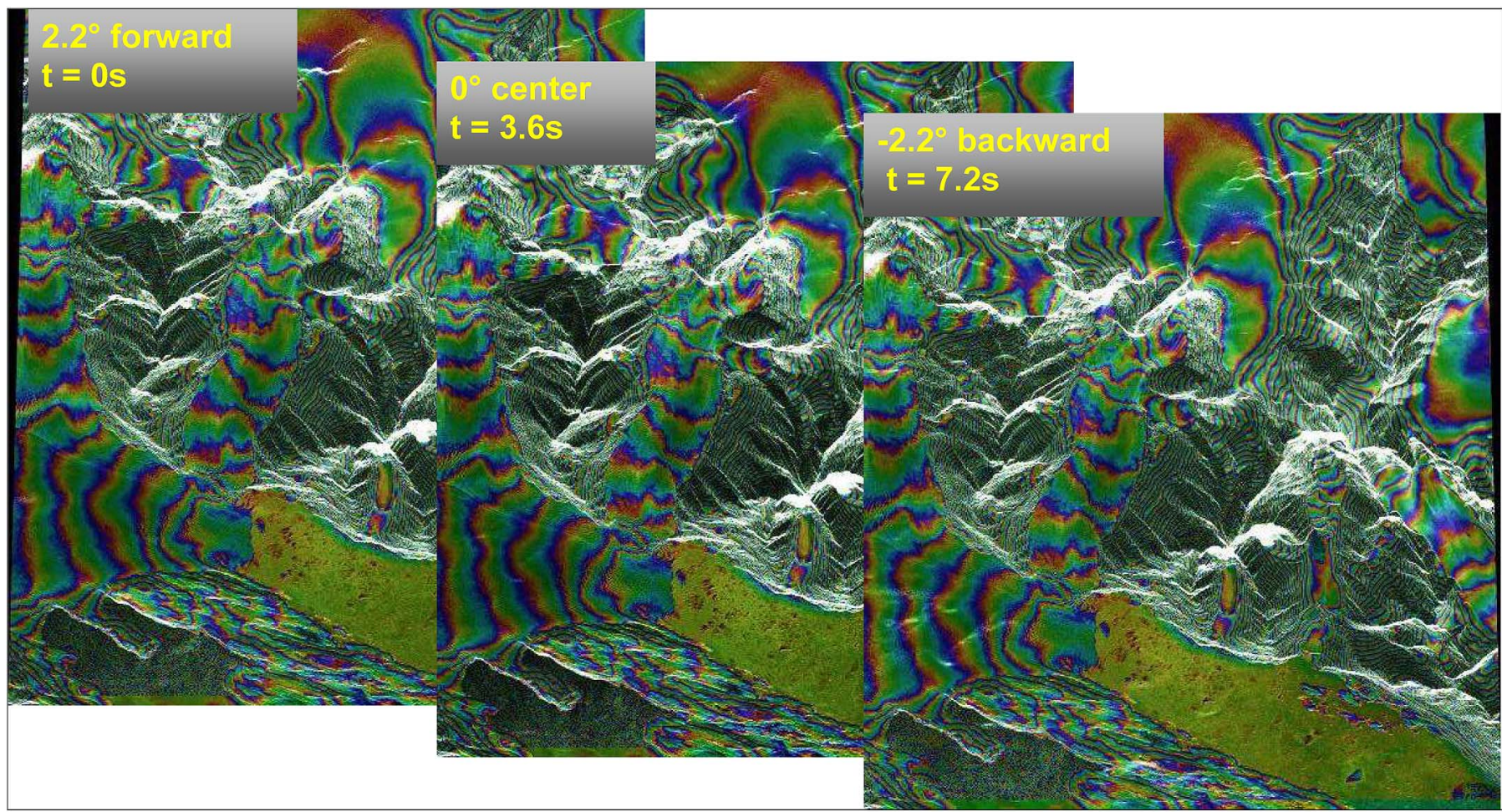

Fig. 21. Short-term interferogram time series of Upsala Glacier, overlap area U2 from Fig. 17. Azimuth direction is on bottom from left to right.
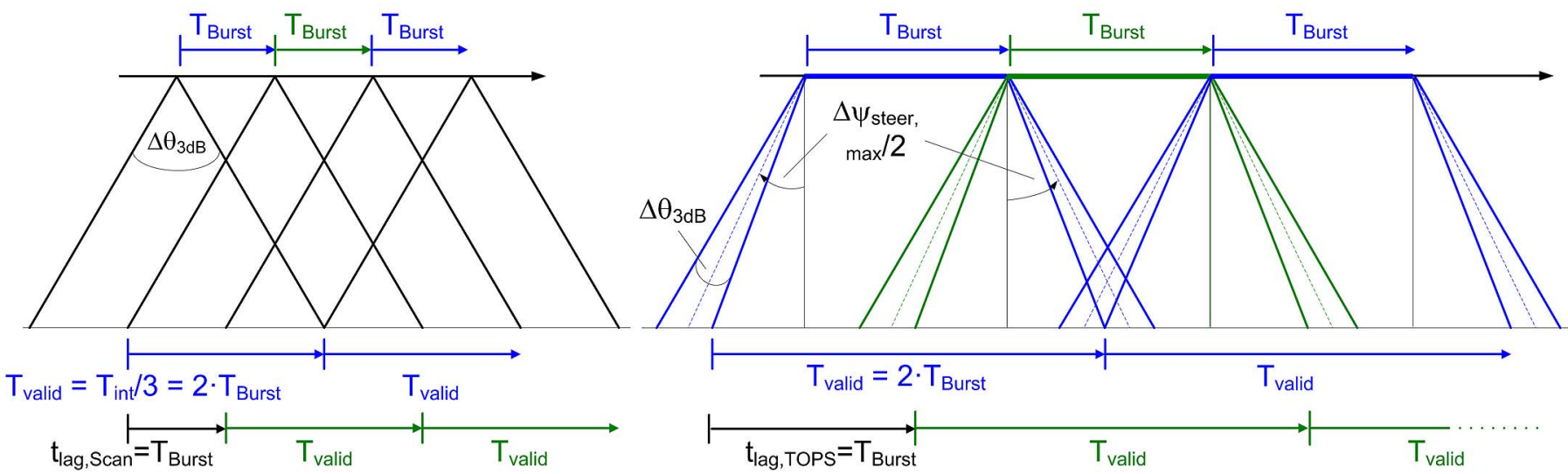

Fig. 22. Time lag for ScanSAR (left) and TOPS acquisition (right).

of the images simultaneously received has been performed in the azimuth spectrum. This approach additionally circumvents the limitation imposed by the grating lobes in phased array antennas.

The azimuth ambiguities have been analyzed for a processed azimuth bandwidth equal to $70 \%$ of the $3-\mathrm{dB}$ bandwidth, and an AASR of $-15 \mathrm{~dB}$ has been estimated.

The BiDi mode has been compared with alternative acquisition strategies for short-term single-satellite repeated SAR acquisitions, i.e., multilook stripmap approach and sequential and toggling fore/aft stripmap approaches. It has been found that the BiDi mode is attractive, particularly due to the circumvention of the grating-lobe restriction, which allows for longer repetition intervals with nonlimited extension of the overlapping area.

The pursuit TanDEM-X configuration during the commissioning phase allowed for the generation of short-term series with two satellites. With the described approach of switching between $\mathrm{BiDi}$ and boresight configuration, six repeated images have been obtained and combined to three repeated interferograms.

A considerable difference has been observed in the backscatter between fore and aft images due to the different azimuth steering angles, e.g., $4.4^{\circ}$ in the Singapore BiDi acquisition example. The BiDi short-term series can be used for change and velocity detection. The example of the Singapore acquisition restricts to a target moving straight into the azimuth direction. As known in the literature, e.g., [9], a target moving into the range direction causes a displacement in the azimuth position. The possibilities of the BiDi imaging mode in terms of velocity measurement is the subject of future research work.

Further possible applications of BiDi include high accuracy measurement of along-track displacement by the exploitation of the widely separated Doppler spectra [22]. Due to the imaging into several directions, BiDi can also support the understanding 
TABLE II

TERraSAR-X Singapore EXAMPLE PARAMETER SET

\begin{tabular}{|c|c|}
\hline \multicolumn{2}{|l|}{ TerraSAR-X system $\&$ antenna } \\
\hline PRF range & $2.8-6.5 \mathrm{kHz}$ \\
\hline \# azimuth sub-arrays & 12 \\
\hline $3 \mathrm{~dB}$ azimuth beamwidth & $0.33^{\circ}$ \\
\hline azimuth sub-array distance & $0.4 \mathrm{~m}$ \\
\hline wavelength & $0.031 \mathrm{~m}$ \\
\hline nominal maximum azimuth steering & $+/-0.75^{\circ}$ \\
\hline \multicolumn{2}{|l|}{ acquisition geometry } \\
\hline orbit height (equator) & $\approx 514 \mathrm{~km}$ \\
\hline TerraSAR-X elevation beam & strip 003 \\
\hline center incidence angle & $\approx 21.5^{\circ}$ \\
\hline near slant range & $542.3 \mathrm{~km}$ \\
\hline forward / backward squint angle (real data) & $2.19^{\circ} /-2.22^{\circ}$ \\
\hline satellite velocity & $7689 \mathrm{~m} / \mathrm{s}$ \\
\hline ground velocity & $7114 \mathrm{~m} / \mathrm{s}$ \\
\hline \multicolumn{2}{|l|}{ raw data acquisition } \\
\hline forward / backward Doppler centroid & $-19.2 / 19.0 \mathrm{kHz}$ \\
\hline PRF & $5860 \mathrm{~Hz}$ \\
\hline instantaneous $3 \mathrm{~dB}$ azimuth bandwidth $\left(\Delta \theta_{3 \mathrm{~dB}}\right)$ & $2851 \mathrm{~Hz}$ \\
\hline \multicolumn{2}{|l|}{ azimuth processing } \\
\hline processed bandwidth & $1995 \mathrm{~Hz}$ \\
\hline Hamming weighting (alpha parameter) & 0.54 \\
\hline azimuth resolution & $3.2 \mathrm{~m}$ \\
\hline image dimension azimuth & $150 \mathrm{~km}$ \\
\hline \multicolumn{2}{|l|}{ range processing } \\
\hline transmitted pulse bandwidth & $100 \mathrm{MHz}$ \\
\hline Hamming weighting (alpha parameter) & 0.54 \\
\hline slant range resolution & $1.9 \mathrm{~m}$ \\
\hline ground range resolution & $5.3 \mathrm{~m}$ \\
\hline image width ground range & $33 \mathrm{~km}$ \\
\hline
\end{tabular}

of the flashing-field effect [19]. Finally, BiDi can be used for improving the radiometric resolution of the standard SAR imaging mode. It is also a very attractive configuration in connection with ScanSAR. In this case, two independent looks can be achieved while maximizing the geometric resolution of the wide swath ScanSAR mode. It is planned to investigate this mode for TerraSAR-X in future research work.

\section{APPENDIX A}

\section{TERraSAR-X EXAMPle PARAMETER SET}

As a reference for the performance calculations and image examples in this paper, Table II summarizes the parameters for the Singapore acquisition shown in Figs. 15, 16, and 20.

\section{APPENDIX B}

\section{REPEATED SCANSAR AND TOPS APPROACH}

Fig. 22 shows on the left a ScanSAR acquisition [12], which repeats the acquisition two times. From the figure, the condition for two-time continuous subswath repetitions can be derived, i.e., the valid burst image $T_{\text {valid,Scan }}$ needs to be twice the raw data burst length $T_{\mathrm{Burst}, \mathrm{Scan}}$. Then, the time lag $t_{\mathrm{lag}, \mathrm{Scan}}$ derives to

$$
\begin{aligned}
t_{\text {lag,Scan }} & =T_{\text {Burst }, \text { Scan }} \\
& =\frac{1}{\left(n_{R}+1\right)} \cdot \frac{r_{0} \cdot \Delta \theta_{3 \mathrm{~dB}}}{V_{g}}=\frac{1}{\left(n_{R}+1\right)} \cdot T_{\mathrm{int}} .
\end{aligned}
$$

The number of repeated acquisitions is $n_{R}$. The ScanSAR time lag is identical with the burst duration and the target integration time $T_{\text {int,Scan }}$. In the case of two repetitions and for the exemplary TerraSAR-X parameter set, $t_{\mathrm{lag}, \text { Scan }}$ results to $0.15 \mathrm{~s}$, which is less than the value for the two-look stripmap approach. The azimuth integration time $T_{\mathrm{int}, \mathrm{Scan}}$ and the azimuth resolution $\rho_{\mathrm{az}, \mathrm{Scan}}$ can be related to the stripmap single-look integration time $T_{\mathrm{int}}$ and resolution $\rho_{\mathrm{az}, \text { strip }}$, i.e.,

$$
\rho_{\mathrm{az}, \text { Scan }}=\rho_{\mathrm{az}, \text { strip }} \cdot\left(n_{R}+1\right) \quad T_{\mathrm{int}, \mathrm{Scan}}=\frac{T_{\mathrm{int}}}{n_{R}+1} .
$$

For two repetitions, the azimuth resolution is three times worse compared with stripmap. The repeated images overlap is not restricted. The SNR is a function of the target azimuth position and, worse for the outer targets. For two repetitions, the worst case SNR deterioration w.r.t. single-look stripmap look is $-0.9 \mathrm{~dB}$, assuming a sinc-like azimuth pattern and an outer target. For a center target, the SNR is $+1.6 \mathrm{~dB}$ better w.r.t. stripmap. Fig. 22 shows that repeated ScanSAR raw data can be always generated from a stripmap acquisition. The data then become ScanSAR by the ScanSAR processing, which generates burst images longer than the raw data bursts to allow for continuous subswath imaging. The two images are formed by time-domain selection. In the two-look stripmap case, the images are formed by Doppler-domain selection or filtering. A ScanSAR acquisition becomes more interesting by generating more than two subswaths, e.g., with different polarizations.

Fig. 22 shows the TOPS mode approach [20], [21] on the right for two-time repeated acquisition. As in ScanSAR, the condition for continuous double acquisition is shown, i.e., the valid burst image extension $T_{\text {valid,TOPS is twice the raw }}$ data burst length $T_{\text {Burst,TOPS }}$. From the drawing, $T_{\text {Burst,TOPS }}$ can be derived, and it is identical to the time lag $t_{\text {lag,TOPS }}$, i.e.,

$$
\begin{aligned}
t_{\text {lag, TOPS }} & =T_{\text {Burst }, \text { TOPS }}=\frac{1}{\left(n_{R}-1\right)} \cdot \frac{r_{0}}{V_{g}} \cdot\left(\Delta \psi_{\text {steer }}-\Delta \theta_{3 \mathrm{~dB}}\right) \\
& =\frac{1}{\left(n_{R}-1\right)} \cdot\left(\frac{r_{0}}{V_{g}} \cdot \Delta \psi_{\text {steer }}-T_{\text {int }}\right) .
\end{aligned}
$$

In our TerraSAR-X example with the maximum steering range $\Delta \psi_{\text {steer }}=1.5^{\circ}$, the time lag $t_{\text {lag,TOPS }}$ is $1.6 \mathrm{~s}$, which is four times shorter than the value for BiDi. The TOPS azimuth resolution is

$$
\begin{aligned}
\rho_{\mathrm{az}, \mathrm{TOPS}} & =\rho_{\mathrm{az}, \mathrm{strip}} \cdot\left(1+\frac{\Delta \psi_{\text {steer }}}{\Delta \psi_{\text {steer }}-\Delta \theta_{3 \mathrm{~dB}}} \cdot \frac{1}{n_{R}-1}\right) \\
T_{\mathrm{int}, \mathrm{TOPS}} & =T_{\mathrm{int}} \cdot\left(1+\frac{\Delta \psi_{\text {steer }}}{\Delta \psi_{\text {steer }}-\Delta \theta_{3 \mathrm{~dB}}} \cdot \frac{1}{n_{R}-1}\right)^{-1}
\end{aligned}
$$

and is 2.3 times the value of the stripmap resolution for the example parameters and $n_{R}=2$ repeated acquisitions. The factor is not 2.0 due to the invalid samples at the edges of each burst image. Note that fine tuning of the performance parameters may allow a slight extension of the nominal steering range in TOPS since the performance of outer burst image targets benefits from integrating highly and moderately steered azimuth patterns, e.g., the SNR and the azimuth ambiguity performance. In case that an extension of the total steering range $\Delta \psi_{\text {steer }}$ to, for example, $2.4^{\circ}$ is possible, the time lag 
would increase to $2.8 \mathrm{~s}$. Note also that the observation angle difference of a point target is $\approx \Delta \psi_{\text {steer }} / 2$ (refer to Fig. 22 ). As in ScanSAR, the repeated images overlap is not restricted, and the SNR deteriorates for targets away from the burst image center. However, compared with ScanSAR, the SNR variation is an order of magnitude less in TOPSAR since it is caused by the azimuth element pattern and not by the array pattern as in ScanSAR [21]. For two repetitions, the repeated TOPS worst case SNR deterioration w.r.t. stripmap-1 look is only $-0.2 \mathrm{~dB}$, assuming a sinc-like azimuth element pattern and an outer burst image target.

In contrast to $\mathrm{BiDi}$, it is not required to double the acquisition PRF in the repeated ScanSAR and TOPS approaches. However, the azimuth resolution is impaired. The Doppler centroid shows a variation with azimuth, which can introduce stronger requirements in terms of the coregistration accuracy of interferometric pairs [7]. The SAR performance is varying in azimuth, considerably in ScanSAR, and much less in TOPS. ScanSAR and TOPS can be used to generate more than two repetitions of the same subswath with, for example, different polarizations.

\section{ACKNOWLEDGMENT}

The authors would like to thank S. Baumgartner for very helpful discussions and his support in the generation of the color composite images.

\section{REFERENCES}

[1] J. Mittermayer and S. Wollstadt, "Simultaneous bi-directional SAR acquisition with TerraSAR-X," in Proc. EUSAR, Aachen, Germany, 2010, pp. 1-4.

[2] K. Ouchi, "On the multilook images of moving targets by synthetic aperture radars," IEEE Trans. Antennas Propag., vol. AP-33, no. 8, pp. 823-827, Aug. 1985.

[3] S. Frasier and A. Camps, "Dual-beam interferometry for ocean surface current vector mapping," IEEE Trans. Geosci. Remote Sens., vol. 39, no. 2, pp. 401-414, Feb. 2001.

[4] J. Mittermayer, M. Younis, R. Metzig, S. Wollstadt, J. Márquez Martínez, and A. Meta, "TerraSAR-X system performance characterization and verification," IEEE Trans. Geosci. Remote Sens., vol. 48, no. 2, pp. 660-676, Feb. 2010.

[5] J. Mittermayer and H. Runge, "Conceptual studies for exploiting the TerraSAR-X dual receive antenna," in Proc. IEEE IGARSS, Toulouse, France, 2003, pp. 2140-2142.

[6] P. Prats, L. Marotti, S. Wollstadt, and R. Scheiber, "Investigations on tops interferometry with TerraSAR-X," in Proc. IGARSS, 2010, pp. 2629-2632.

[7] P. Prats, R. Scheiber, L. Marotti, S. Wollstadt, and A. Reigber, "TOPS interferometry with TerraSAR-X," IEEE Trans. Geosci. Remote Sens., vol. 50, no. 8, pp. 3179-3188, Aug. 2012.

[8] F. López-Dekker, P. Prats, F. De Zan, S. Wollstadt, D. Schulze, G. Krieger, and A. Moreira, "Demonstration of SAR interferometry under crossing orbits using TerraSAR-X and TanDEM-X," in Proc. IGARSS, Vancouver, BC, Canada, Jul. 2011, pp. 3472-3475.

[9] S. V. Baumgartner and G. Krieger, "Large along-track baseline SAR-GMTI: First results with the TerraSAR-X/TanDEM-X satellite constellation," in Proc. IGARSS, Vancouver, BC, Canada, Jul. 2011, pp. 1319-1322.

[10] U. Wegmüller, D. Walter, V. Spreckels, and C. L. Werner, "Nonuniform ground motion monitoring with TerraSAR-X persistent scatterer interferometry," IEEE Trans. Geosci. Remote Sens., vol. 48, no. 2, pp. 895-904, Feb. 2010.

[11] J. Hueso Gonzalez, M. Bachmann, and H. Hofmann, "TanDEM-X commissioning phase status," in Proc. IGARSS, Honolulu, HI, 2010, pp. 2633-2635.
[12] Moreira, J. Mittermayer, and R. Scheiber, "Extended chirp scaling algorithm for air- and spaceborne SAR data processing in StripMap and ScanSAR imaging modes," IEEE Trans. Geosci. Remote Sens., vol. 34, no. 5, pp. 1123-1136, Sep. 1996.

[13] J. Mittermayer, B. Schättler, and M. Younis, "TerraSAR-X commissioning phase execution summary," IEEE Trans. Geosci. Remote Sens., vol. 48, no. 2, pp. 649-659, Feb. 2010.

[14] G. Krieger, A. Moreira, H. Fiedler, I. Hajnsek, M. Werner, M. Younis, and M. Zink, "TanDEM-X: A satellite formation for high resolution SAR interferometry," IEEE Trans. Geosci. Remote Sens., vol. 45, no. 11, pp. 3317-3341, Nov. 2007.

[15] S. Suchandt, H. Runge, H. Breit, U. Steinbrecher, A. Kotenkov, and U. Balss, "Automatic extraction of traffic flows using TerraSAR-X alongtrack interferometry," IEEE Trans. Geosci. Remote Sens., vol. 48, no. 2, pp. 807-819, Feb. 2010.

[16] R. Romeiser, S. Suchandt, H. Runge, U. Steinbrecher, and S. Grünler, "First analysis of TerraSAR-X along-track InSAR-derived current fields," IEEE Trans. Geosci. Remote Sens., vol. 48, no. 2, pp. 820-829, Feb. 2010.

[17] T. P. Anguela, M. Zribi, N. Baghdadi, and C. Loumagne, "Analysis of local parameters with TerraSAR-X radar data over bare agricultural fields," IEEE Trans. Geosci. Remote Sens., vol. 48, no. 2, pp. 874-881, Feb. 2010.

[18] S. Wollstadt, P. Lopez-Dekker, P. Prats, F. De Zan, T. Busche, and G. Krieger, "Interferometric crossing orbit experiment using TerraSAR-X and TanDEM-X," in Proc. FRINGE, Frascati, Italy, 2011.

[19] U. Wegmüller, R. A. Cordey, C. Werner, and P. J. Meadows, "Flashing files in nearly simultaneous ENVISAR and ERS-2 C-Band SAR images," IEEE Trans. Geosci. Remote Sens., vol. 44, no. 4, pp. 801-805, Apr. 2006.

[20] F. De Zan and A. Monti Guarnieri, "TOPSAR: Terrain observation by progressive scan," IEEE Trans. Geosci. Remote Sens., vol. 44, no. 9, pp. 2352-2360, Sep. 2006.

[21] A. Meta, J. Mittermayer, P. Prats, R. Scheiber, and U. Steinbrecher, "TOPS imaging with TerraSAR-X: Mode design and performance analysis," IEEE Trans. Geosci. Remote Sens., vol. 48, no. 2, pp. 759-769, Feb. 2010.

[22] R. Scheiber and A. Moreira, "Coregistration of interferometric SAR images using spectral diversity," IEEE Trans. Geosci. Remote Sens., vol. 38 , no. 5, pp. 2179-2191, Sep. 2000.

[23] R. Bamler and M. Eineder, "Accuracy of differential shift estimation by correlation and split-bandwidth interferometry for wideband and delta-k SAR systems," IEEE Geosci. Remote Sens. Lett., vol. 2, no. 2, pp. 151-155, Apr. 2005.

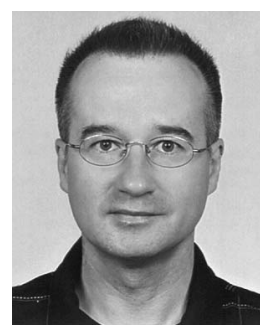

Josef Mittermayer was born in Wartenberg, Oberbayern, Germany, in 1967. He received the Diploma in electrical engineering from the Technical University of Munich, Munich, Germany, in 1995, with a thesis on ScanSAR processing, the M.S degree in space system engineering from the Delft University of Technology, Delft, The Netherlands, in 2004, and the Ph.D. degree from the University of Siegen, Siegen, Germany, in 2000, in the field of spotlight-SAR processing.

From 1994 to 2001, he was with the Signal Processing Group, Microwaves and Radar Institute, German Aerospace Center (DLR), Bavaria, Germany. From 2002 to 2008, he was working in the TerraSAR-X project with DLR. From January 2004 until the end of the commissioning phase in 2008, he was the Group Leader and the Project Manager of System Engineering and Calibration, one of the three subprojects that form the TerraSAR-X Ground Segment. In addition, he was technically responsible for the TerraSAR-X commissioning phase. He is currently as Scientist with the Microwaves and Radar Institute, working in the field of SAR system engineering and SAR processing.

Dr. Mittermayer and his colleagues were recipients of the IEEE Geoscience and Remote Sensing Society Transactions Prize Paper Award for a paper on airand spaceborne stripmap and ScanSAR processing in 1996. In 2001, he was a recipient of the DLR Science Award for his work on spotlight-SAR processing. In 2011, he was a recipient of the DLR Forschungssemester for his contribution to the TerraSAR-X project. 


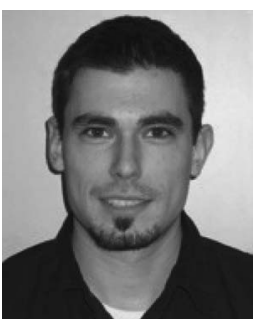

Steffen Wollstadt received the Dipl.-Ing. (M.Sc.) degree in electrical engineering from the Technical University of Darmstadt, Darmstadt, Germany, in 2005, with a thesis on metamaterial-based microstrip antenna design.

Since 2006, he has been with the Microwaves and Radar Institute, German Aerospace Center (DLR), Bavaria, Germany. From 2006 to 2008, he was a Project Engineer with the Satellite Synthetic Aperture Radar (SAR) Systems department in the System Engineering and Calibration part of the TerraSAR-X ground segment, where he worked on the TerraSAR-X and TanDEM-X instrument command generation. Since 2009, he has been with the Radar Concepts Department, Microwaves and Radar Institute, where he has been working on Terrain Observation by Progressive Scans (TOPS) Sentinel-1 image quality and SAR performance investigations. His current main interests focus on experiments with TerraSAR-X and TanDEM-X about novel imaging modes, particularly focusing on interferometric problems.

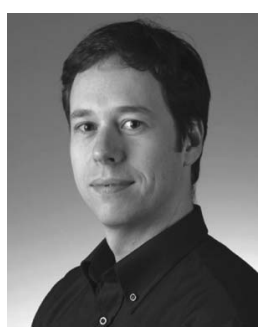

Pau Prats-Iraola (S'03-M'06) was born in Madrid, Spain, in 1977. He received the Ingeniero degree in telecommunication engineering and the Ph.D. degree from the Universitat Politècnica de Catalunya (UPC), Barcelona, Spain, in 2001 and 2006, respectively.

In 2001, he was a Research Assistant with the Institute of Geomatics, Castelldefels, Spain, designing a subaperture synthetic aperture radar (SAR) processor. In 2002, he was with the Department of Signal Theory and Communications, UPC, where he worked in the field of airborne repeat-pass interferometry and airborne differential SAR interferometry. From December 2002 to August 2006, he was an Assistant Professor with the Department of Telecommunications and Systems Engineering, Universitat Autònoma de Barcelona, Barcelona. Since 2006, he has been with the Microwaves and Radar Institute, German Aerospace Center (DLR), Bavaria, Germany, where he has been the Head of the Multimodal Algorithms Group since 2009. His research interests include air- and spaceborne SAR processing, SAR interferometry, differential SAR interferometry, and motion compensation for airborne systems.

Dr. Prats-Iraola was the recipient of the first prize of the Student Paper Competition of the IEEE International Geoscience and Remote Sensing Symposium 2005 Conference held in Seoul, Korea.



Paco López-Dekker (S'98-M'03) was born in Nijmegen, The Netherlands, in 1972. He received the Ingeniero degree in telecommunication engineering from the Universitat Politècnica de Catalunya (UPC), Barcelona, Spain, in 1997, the M.S. degree in electrical and computer engineering from the University of California, Irvine, in 1998, under the Balsells Fellowships, and the Ph.D. degree from the University of Massachusetts, Amherst, in 2003, for his research on clear-air imaging radar systems to study the atmospheric boundary layer.

From 1999 to 2003, he was with the Microwave Remote Sensing Laboratory, University of Massachusetts. In 2003, he was a Research Scientist with Starlab, where he focused on the development of Global Navigation Satellite System Reflectometry (GNSS-R) sensors. From 2004 to 2006, he was a Visiting Professor with the Telecommunications and Systems Engineering Department, Universitat Autonoma de Barcelona. In March 2006, he was with the Remote Sensing Laboratory, UPC, where he conducted research on bistatic synthetic aperture radar (SAR) under a five-year Ramon y Cajal Grant. At the university, he taught courses on signals and systems, signal processing, communications systems and radiation, and guided waves. Since November 2009, he has been leading the SAR Missions Group, Microwaves and Radar Institute, German Aerospace Center (DLR), Bavaria, Germany. His current research focuses on the study of future SAR missions and novel mission concepts.



Gerhard Krieger (M'04-SM'09) received the Dipl.-Ing. (M.S.) and Dr.-Ing. (Ph.D.) degrees (with honors) in electrical and communication engineering from the Technical University of Munich, Munich, Germany, in 1992 and 1999, respectively.

From 1992 to 1999, he was with the Ludwig Maximilians University, Munich, where he conducted multidisciplinary research on neuronal modeling and nonlinear information processing in biological and technical vision systems. Since 1999, he has been with the Microwaves and Radar Institute (HR), German Aerospace Center (DLR), Bavaria, Germany, where he developed signal and image processing algorithms for a novel forward-looking radar system employing digital beamforming on receive. From 2001 to 2007, he led the New Synthetic Aperture Radar (SAR) Missions Group, which pioneered the development of advanced bistatic and multistatic radar systems as exemplified by the forthcoming TanDEM-X mission, as well as innovative multichannel SAR techniques and algorithms for high-resolution wide-swath SAR imaging. Since 2008, he has been the Head of the new Radar Concepts Department, Microwaves and Radar Institute, DLR, Bavaria, Germany. He has authored more than 40 peer-reviewed journal papers, four invited book chapters, and about 250 conference papers. He is the holder of five patents. His current research interests focus on the development of multichannel radar techniques and algorithms for innovative Multiple Input Multiple Output (MIMO) SAR systems, the demonstration of novel interferometric and tomographic earth observation applications, and the conceptual design of advanced bi- and multistatic radar missions.

Dr. Krieger was a recipient of several national and international awards, including the W. R. G. Baker Prize Paper Award from the IEEE Board of Directors and the Transactions Prize Paper Award of the IEEE Geoscience and Remote Sensing Society.

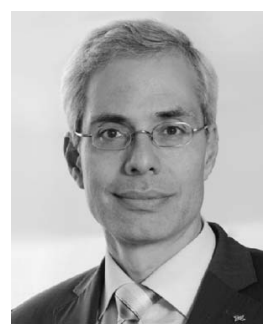

Alberto Moreira (S'96-F'04) received the B.S.E.E. and M.S.E.E. degrees from the Aeronautical Technological Institute (ITA), São José dos Campos, Brazil, in 1984 and 1986, respectively, and the Eng. Dr. degree (with honors) from the Technical University of Munich, Munich, Germany, in 1993.

From 1996 to 2001, he was the Chief Scientist and Engineer with the Synthetic Aperture Radar (SAR) Technology Department, German Aerospace Center (DLR), Bavaria, Germany. Under his leadership, the DLR airborne SAR system has been upgraded to operate in innovative imaging modes such as polarimetric SAR interferometry and SAR tomography. Since 2001, he has been the Director of the Microwaves and Radar Institute, DLR. The institute contributes to several scientific programs and space projects for actual and future air- and spaceborne SAR missions such as TerraSAR-X, TanDEM-X, and Sentinel-1. The mission TanDEM-X, led by his institute, has successfully started the operational phase in December 2010. He is the Initiator and the Principal Investigator for this mission. Since 2003, he has been a Full Professor with the Karlsruhe Institute of Technology, Karlsruhe, Germany, in the field of microwave remote sensing. He has more than 300 publications in international conferences and journals. He is the holder of 15 patents in the radar and antenna field. His professional interests and research areas encompass radar end-to-end system design and analysis, innovative microwave techniques and system concepts, signal processing, and remote sensing applications.

Dr. Moreira is a member of the IEEE Geoscience and Remote Sensing Society (GRSS) Administrative Committee (1999-2001, 2004-2013, 2010 as President, and 2011-2013 as Past President), was the Founder and Chair of the GRSS German Chapter (2003-2008), and was the Associate Editor for the IEEE Geoscience And Remote Sensing Letters (2003-2007) and for the IEEE Transactions on Geoscience and Remote Sensing (2005-2011). He and his colleagues were recipients of the GRSS Transactions Prize Paper Awards in 1997, 2001, and 2007, and the IEEE W. R. G. Baker Award in 2012. He is also the recipient of the DLR Science Award (1995), the IEEE Nathanson Award for the Young Radar Engineer of the Year (1999), and the IEEE Kiyo Tomiyasu Field Award (2007). He served as a member of the Board of Directors of the Information Technology Society of the German Association for Electrical, Electronic, and Information Technologies (2003-2008) and as the Chair of the Scientific and Technical Council of DLR (2009-2011). He has contributed to the successful series of the European SAR conferences (EUSAR) since 1996 as a member of the Technical Program Committee, Technical Chairman (2000), Awards Chairman (2002-2004), General Chairman (2006), and Cochairman (2008). He serves as the General Cochair for IEEE International Geoscience and Remote Sensing Symposium 2012 in Munich. 